\title{
Implementation of Context Specific Diagnostics, Strategies and Resources for PMTCT Scale-up Programming in Conflict Affected Communities in Jos, Nigeria
}

\author{
Tinuade Abimbola Oyebode ${ }^{1,2, ~}$, Zuwaira Hassan ${ }^{1,3}$, Tolulope Afolaranmi ${ }^{1,3}$, Musa Tanko Umar ${ }^{1}$, \\ Francis Magaji ${ }^{4}$, Maria Pawa ${ }^{5}$, Patrick Akande ${ }^{6}$, Solomon Sagay ${ }^{1,2}$, Jerry Gwamna ${ }^{6}$, \\ Prosper Okonkwo ${ }^{7}$, Phyllis Kanki ${ }^{8}$ \\ ${ }^{1}$ Faculty of Medical Sciences, University of Jos, Jos, Nigeria \\ ${ }^{2}$ Department of Obstetrics and Gynaecology, Jos University Hospital, Jos, Nigeria \\ ${ }^{3}$ Department of Community Medicine, Jos University Hospital, Jos, Nigeria \\ ${ }^{4}$ Plateau AIDS Control Agency (PLACA), Jos, Nigeria \\ ${ }^{5}$ State AIDS/STI Control Program (SASCP), Plateau State Ministry of Health, Jos, Nigeria \\ ${ }^{6}$ Center for Disease Control and Prevention (CDC), Abuja, Nigeria \\ ${ }^{7}$ AIDS Prevention Initiative in Nigeria (APIN), Abuja, Nigeria \\ ${ }^{8}$ Infectious Diseases \& Immunology, Harvard School of Public Health, Boston, MA, USA
}

\section{Email address:}

tinuadeoyebode@yahoo.com (T. A. Oyebode), zuwairahassan@yahoo.com (Z. Hassan), toluene42002@gmail.com (T. Afolaranmi), babatanko3001@gmail.com (M. T. Umar), ikoseng@yahoo.com (F. Magaji),mariapawa@yahoo.com (M. Pawa), pakande@apin.org.ng (P. Akande), atsagay@yahoo.com (S. Sagay), Gwamna」@ng.cdc.gov (J. Gwamna), pokonkwo@apin.org.ng (P. Okonkwo), pkanki@hsph.harvard.edu (P. Kanki)

${ }^{*}$ Corresponding author

\section{To cite this article:}

Tinuade Abimbola Oyebode, Zuwaira Hassan, Tolulope Afolaranmi, Musa Tanko Umar, Francis Magaji, Maria Pawa, Patrick Akande, Solomon Sagay, Jerry Gwamna, Prosper Okonkwo, Phyllis Kanki. Implementation of Context Specific Diagnostics, Strategies and Resources for PMTCT Scale-up Programming in Conflict Affected Communities in Jos, Nigeria. International Journal of HIV/AIDS Prevention, Education and Behavioural Science. Vol. 7, No. 1, 2021, pp. 15-26. doi: 10.11648/j.ijhpebs.20210701.13

Received: April 28, 2021; Accepted: May 14, 2021; Published: May 26, 2021

\begin{abstract}
The 2013 WHO HIV guidelines provided effective antiretroviral regimens to reduce perinatal transmission to below $2 \%$. The option-B approach of providing antiretroviral drugs was adopted by Nigeria, which contributed $32 \%$ of global gaps in Preventing Mother to child transmission (PMTCT). In Plateau State, which had 7.7\% HIV prevalence, incessant ethnoreligious conflict created challenges impacting on HIV service delivery and access to treatment centers. PMTCT diagnostics conducted by the lead HIV implementing Partner (IP), revealed that several communities in Jos, Plateau State, lacked HIV treatment centers, but were also unable to access existing centers because of conflict related partitioning of Jos, calling for specialized strategies and collaboration to scale-up to affected communities. To bridge existing challenges related to distrust amongst communities, the intervention strategy identified six community oriented resource persons (CORPs), of same ethnoreligious dispensation as people in affected communities, who also possessed HIV programing competencies, to lead the intervention. The project methodology included engagement of community gatekeepers and Plateau HIV stakeholders, who generated context specific strategies to enter these communities and scale-up HIV/PMTCT. The lead CORPs included a female public health/HIV physician, another clinician who owned a community hospital, a HIV laboratory personnel, a HIV trained Data officer, a religious cleric/youth leader and a female expert patient cum member of Federation of Muslim women association of Nigeria (FOMWAN). Collaborating with various stakeholders, they birthed a community faith based organization they called Muslim Health Initiative of Nigeria (MUHIN). This served as platform for community engagement to scale-up HIV/PMTCT services. The Lead HIV Partner supported, engaged and funded MUHIN to provide context specific scale-up to address existing gaps. MUHIN identified, assessed, upgraded and activated twenty-eight community clinics for HIV/PMTCT service deliver, building on existing Maternal, child and New-born health (MNCH) structures. They provided
\end{abstract}


HIV trainings, MNCH materials, national data-capture tools and capacity building to the identified facilities, staff and CORPs. They stratified according to facility capacity, and linked them using the Hub-and-spoke model, to provide HIV testing, PMTCT and Antiretroviral therapy (ART) services. In order to bridge existing human resource for health gaps existing at the clinics, community health workers and HIV positive women who had successfully completed PMTCT programs were engaged and trained according to task shifting and task sharing (TSTS) guidelines, in preparation for HIV/PMTCT activation using HCT as entry. We conclude that detailed diagnostics, planning and utilization of context-specific strategies including TSTS are critical for successful project outcomes.

Keywords: Prevention of Mother to Child Transmission, Human Immunodeficiency Virus, Plateau State, Community Oriented Resource Persons, Ethnoreligious, Conflict and Scale-up

\section{Introduction}

Data from UNAIDS indicate Nigeria still has the second largest global HIV epidemics and one of the highest rates of new infection in sub-Saharan Africa, and many HIV infected Nigerians are unaware of their status [1]. It indicates Nigeria still falls short of providing recommended numbers of HIV testing and counselling (HTC) sites, and poor access to antiretroviral treatment (ART) remains a challenge for people living with HIV (PLHIV), with consequent high AIDSrelated deaths.

An estimated 58\% of Nigerian PLHIVs are women [2], partly because of gender inequality, patriarchy and socio cultural factors that subordinate women/girls and predispose them to infection [3]. Nigeria maintains position 122 out of 144 because of its 'gender gap' and unequal power balances between men and women [4]. This means women have limited negotiating skills and may be unable to dictate their own sexual preferences, contraception use, children number and spacing, which all increase risks of contracting HIV and developing complications [5]. This is relevant in Nigeria, where patriarchy, religion and culture reinforce the low status of woman, and many women depend on men and require permission from male authority figures to access social, economic and health services [6]. Considering that Plateau has encountered conflicts resulting in destruction of homes, health centers, livelihoods and people displacements, which together predispose women/girls to unprotected and unconsented sex, which increase infections, impede treatment access, increase unmet PMTCT needs, with approximately $26.9 \%$ of global HIV MTCT happening in Nigeria [7]. An estimated $34.7 \%$ received HIV during antenatal care, and approximately $32 \%$ of pregnant HIV positive women received antiretroviral treatment for PMTCT [8], with consequent high rates $(22 \%)$ of perinatal HIV transmission and low HIV early infant diagnosis (HEI) rates [7].

Nigeria bears second largest burden of HIV in Africa, second to South Africa, and only one-third of the estimated 1.4 million PLHIVs requiring ART were accessing treatment at the end of 2012 [9], as universal access remain a challenge with only 6.6 million $(47 \%)$ of the estimated 14.2 million people eligible for treatment had access, with many rural communities unable to access HIV/AIDS services [10]. On account of Nigeria's high HIV burden but having the second lowest PMTCT ART coverage, it was enlisted among 23 priority UNAIDS' countries for PMTCT [11]. The number of health facilities providing ANC services and women assessing PMTCT remains low, with only 7,265 health facilities providing PMTCT by 2015 [8]. To close this gap, Nigeria aims to have $95 \%$ of health facilities providing PMTCT services by 2021 [11] PMTCT gap is a longstanding problem, and by 2014 Plateau was named among the $12+1$ high HIV-burden state in Nigeria with $7.7 \%$ prevalence [9].

Jos occupies the middle of Nigeria, where the majorly Muslim north and Christian south meet. The metropolis had an estimated population of 794,000 persons in 2014 with an annual growth rate ranging 1.9 and $2.4 \%$ [12]. Tin mining activities during colonial times attracted migrants from all over Nigeria to Jos, so that the considerable safety was recognized, making it safe for influx of displaced persons who migrated from other parts of north Nigeria affected majorly by religious crises between 1980 and 2010 [13]. The migrations subsequently led to overpopulated urban slums, which are postulated to have incited further ethnoreligious conflicts in the previously safe town [14]. This resulted in high population build-up in the slums of Jos particularly Angwan Rogo, Rikkos Bauchi Road, Ali Kazaure and other majorly Hausa/Fulani muslims, while fleeing Christians moved to Christian dominated slums like Angwan Rukuba, Tudun Wada, Jenta, Gada Biyu and Congo Russia [15]. However, migrations and displacements continued with evolution of demographics.

Analysis of interactions between Conflict and HIV is critical in improving access to HIV prevention, treatment, care and support for people during and after conflict, and it was postulated that Millennium Development Goal (MDG) 6 would not be met if HIV services do not reach conflict areas, displaced populations, migrants, and uniformed services that interact with these populations [16]. This remains a major consideration to change Nigeria's unmet PMTCT needs in conflict states like Plateau.

Diagnostics of PMTCT/HIV Gaps in Plateau including mapping of facilities with comprehensive HIV services was done, which revealed an imaginary line separating the centers from some densely populated communities in especially Jos North. They communities included, but were not limited to Ali Kazaure, Angwan Rogo, Angwan Rimi, Bauchi Road, Congo Russia, Corner Shagari, Dogon Dutse, Fillin Ball, Gangare, Masalacin Jumaa, Masalacin Idi, Naraguta Village, Nasarawa, Rikkos and Yan Shanu. None of these 
communities had comprehensive HIV centers and the crises related partitioning of Jos also restricted access to other parts of the Jos that had these centers. This created a crises context specific unmet need.

The facility mapping revealed seven supported Comprehensive HIV treatment sites within Jos namely The Our Lady of Apostles Hospital, (OLA), Jos, Bingham University Teaching Hospital (BUTH), Jos, Faith Alive Foundation (FAF), Jos, Jos University Teaching Hospital (JUTH), Jos, Plateau State Specialist Hospital (PSSH), Jos, SOLAT hospital, Jos and Comprehensive health Centre, Dadin Kowa, Jos.

Between 2001 and 2011, the crisis over 'indigene' rights and political representation in Jos metamorphosed into a protracted communal conflict affecting most parts of Plateau. An estimated 4,000 to 7,000 people were killed since late 2001, when the first major riot in over three decades broke out in Jos, requiring heavy presence and efforts of military/police forces to maintain calm in Jos by 2010 [18]. Tensions between the various ethnic groups founded upon resource allocation, electoral competition, religious domination and land contestations created disharmony, with associated increased small weapon numbers, worsening tension and violence within Jos and towns all over Plateau. The dispute over indigene and settlers "rights" to land, power and resources features prominently [19], and the crises is attributed to failure to amend the constitution to privilege broad-based citizenship over exclusive indigene status and ensure that residency rather than indigeneity determines citizens' rights [20]. The State became deeply enmeshed ethno-religious conflicts characterized by genocidal attacks, bombing, maiming, killings, loss of investments and properties worth billions of Naira, with one revelation that lack of political representation, discrimination, marginalization, neglect, poverty, unemployment, identity, and elite manipulation were the major causes of the crisis [21]. The claims to 'indigene' status and ownership of Jos are fiercely contested between the majorly Christian native tribes and settler Hausa/Fulani, and ethnicity and religion reinforces the boundaries between them and manifesting in statewide urban and rural conflicts. The violence created distrust and prevents access to other parts of the town/state and services they offer.

However, former Governor Solomon Lar disagreed with ethnoreligious assertions but attributed politics as cause of conflicts [22]. A state of emergency was declared by the federal government in 2004, when about 700 people were killed during the Yelwa attack. Clashes between Muslim and Christian youths erupted in Jos in 2008, killing at least 700 , another major one in 2010, where over 1,000 persons died [23]. The internally displaced persons (IDP) in Jos increased to 220,000 by 2004 [24], while 2008 riot displaced over 10,000 persons, and another 18,000 after the 2010 violence [25].

All factions suffered destruction of lives, property and livelihoods leading to the redefinition of Jos, its communities and Plateau's indigenes feel threatened with marginalization and are unwilling to relinquish exclusive indigene privileges, while the violence and massacres left many residents traumatized and many neighbourhoods in Jos have become segregated by distrust, ethnicity and religion, and 'no-go areas' have arisen and created altered patterns of residency, business, transportation and trade requiring definitive solutions [18]. Currently, within Jos, there are communities where people of same religion/ethnicity reside, work and access healthcare that cannot be assessed by other religion/ethnicities. The unsettled, unsafe and/or inaccessible terrains create barriers to coverage, utilization and access to healthcare including HIV.

Complex interactions exist between protracted conflicts and lives of especially women/girls and HIV. Disruptions of schooling and livelihoods, poverty, displacement, poor shelter, and attendant vulnerabilities, increase rates of transactional, unconsented, unplanned and unprotected sex all increase HIV transmission rates. Conversely, access to healthcare including sexual and reproductive health commodities is limited, with below $40 \%$ of operational health facilities in conflict-stricken region, conferring adverse outcomes on SRH of women and girls in conflict regions [26]. Health infrastructure are damaged and difficult to access, staff are killed/displaced, SRH/MNCH/PMTCT commodities logistics are disrupted, out-of-pocket expenses are unaffordable and healthcare is disrupted. Also, mass deployment of military personnel into civilian communities are associated and human rights abuses, including sexual violence. These increase vulnerability of women and girls to HIV infection as restricted movements, destruction of roads and others prevent access Sexual and Reproductive Health Services (SRH) services including maternity services, HIV testing, PMTCT services and Antiretroviral therapy [27].

The Tenth Parallel North has been described as the "fault line where Islam and Christianity meet and clash." In Africa, it passes west to east through northern Nigeria, Cameroon, the Central African Republic, South Sudan, Sudan and Somalia, all of which have experienced major ethnic, religious or terrorism-related conflict leading to fragile societies requiring humanitarian assistance [28]. Plateau State occupies the middle of Nigeria between the predominantly Muslim north and majorly Christian south.

Since 2010, Plateau State began to experience recurrent ethno-religious crises, with massive destruction of lives and properties and displacement of persons. This led to distrust and a progressive segregation of the populace across ethnoreligious lines, and partitioning of the inhabitants. The Jos metropolis, capital of Plateau State was prominently affected and people relocated into new environments based on ethnicity and religion [15].

The partitioning of Jos restricted residents to utilizing health facilities within the communities, majority of which were lacking HIV/AIDS prevention/treatment services based on known locations of comprehensive treatment facilities. Reduction in HIV transmission and elimination of mother to child transmission (eMTCT) of HIV is a global priority but inequities and disparities in access remain impediments to its 
attainment [11]. Significant progress has been made in developed settings, while only $15 \%$ to $30 \%$ of eligible women are able to complete the prevention of mother to child transmission (PMTCT) cascade in resource constrained setting [29] including Nigeria. Employing evidence based approaches to identifying specific barriers, addressing them through existing community structures and closing these gaps becomes tenable. It was against this backdrop, that we identified fourteen major communities in Jos that lack HIV/PMTCT services and conceptualized an engagement strategy with CORPs to improve coverage, uptake and retention of HIV/PMTCT services.

Elimination of HIV mother to child transmission is a priority globally but severe regional inequities prevent its attainment. Remarkable progress has been made in developed countries, while approximately $15 \%$ to $30 \%$ of eligible women are able to complete the PMTCT cascade in resource constrained settings [29]. Several barriers preventing optimal access and utilization of prevention of mother to child

$$
\text { Awareness } \Rightarrow \begin{gathered}
\text { HIV } \\
\text { Testing }
\end{gathered} \Rightarrow \text { Diagnosis } \Rightarrow \begin{gathered}
\text { Treatment } \\
\text { Initiation } \\
\text { for PMTCT }
\end{gathered} \Rightarrow \begin{gathered}
\text { Adherence } \\
\text { \& Follow }
\end{gathered} \Rightarrow \begin{gathered}
\text { Clinical \& } \\
\text { Psychological } \\
\text { Outcomes }
\end{gathered}
$$

Figure 1. HIV Treatment and Cascade.

With the various barriers encountered between each stage, a steady reduction in the successful achievement of each successive step occurs [33].

In some communities in Jos and environs, PMTCT gaps included barriers to accessing designated comprehensive HIV facilities. The conceptualization and selection of community oriented Muslim HIV care providers to inaugurate Muslim Health Initiative in Nigeria, a faith-based/Community Based Organization was to eliminate this barrier to access and use the HIV Program to strengthen Maternal/Child Services.

\section{Methods}

Plateau state PMTCT diagnostics and facility mapping revealed that most comprehensive HIV treatment centers were dispersed majorly on one side of Jos based on partitioning lines resulting from the conflicts. These facilities also constitute the major comprehensive secondary and tertiary health facilities with capacity to provide quality healthcare services beyond MNCH and PMTCT. These affected communities majorly in Jos North LGA lacked comprehensive HIV facilities, even when healthcare would be necessarily sought where people reside, during partitioning from ethnoreligious conflict.

This was a call to Plateau state Ministry of health, its HIV implementing partners and other stakeholders to identify strategies to overcome the gaps in HIV service delivery. The aim would be identify all affected communities, characterize peculiar gaps to guide community-based approaches to closing them, and increase uptake, retention, adherence and positive psychosocial outcomes in PMTCT programs in resource-poor countries [2]. transmission (PMTCT) services occur outside the healthcare facility and within communities. The specific barriers to access must be identified among communities and the evidence utilized in addressing barriers and increase service utilization in order to eliminate paediatric HIV. In order to close the gaps, proper understanding of context-specific barriers and subsequent design of evidence based interventions must be tailored to each setting [30]. The PMTCT cascade will be near nonexistent if persons cannot access comprehensive care. A comprehensive package of HIV services requires elements across the full continuum, including prevention, testing, treatment and care [31].

The outcomes of PMTCT programs are depicted along a treatment continuum or "cascade," which depicts an individual's trajectory from before HIV diagnosis, through each stage of successful enrolment in treatment and care, to measurable improvements in physical and mental health [32], and in this case PMTCT of HIV.

\subsection{Identification of Suitable Community Resource Persons and Team Constitution}

Considering identified challenges and need to scale-up into the identified communities, a head hunt was commenced for resource persons in HIV programs and service delivery. They would also double as Community oriented Resource Persons (CORPs), of same faith/ethnicity, they should work or reside, interphase with and be known within any of target communities.

Using set criteria, we identified suitable health providers, competent in HIV services and spanning across critical HIV program areas. Individuals, some of who interphase with HIV service delivery at the major Comprehensive treatment sites, but well accepted in the communities were selected. They each had experience working with community groups including Islamic, women, youths, clerics and NonGovernmental Community based organizations. They were of Islamic Faith and Hausa/Fulani ethnicity, some resided within target communities and others provided Healthcare in hospitals within target communities. They had all received HIV trainings in their areas of specialty by the lead HIV Partner.

We commenced discussions and received inputs into selected communities, obtained their buy into the concept, affirmation of participation, proposed community entry and project implementation strategies. They consisted a Consultant Public Health and lead HIV Clinician and member of Federation of Muslim Women association of Nigeria (FOMWAN), leader of the Islamic pilgrimage medical team that escorted muslim faithfuls to perform hajj in Saudi Arabia. Second was a medical Doctor and known 
Community leader who ran a community hospital, the third was a competent HIV trained Laboratory scientist. There was a HIV data officer who doubled as community youth leader and the fifth was a community Islamic cleric. The sixth was a female PLHIV and HIV support group leader, expert patient that successfully completed PMTCT and member of FOMWAN. They all had experience working with community groups, Islamic women, youths, clerics, community NGOs/CBOs and Persons living with HIV/AIDS (PLHIVs) and would be the focal persons to lead the initiative.

\subsection{Pre-inception Activities and Set up of Faith Based Community Organization}

A concept note was developed after documenting the communities around Jos that could not assess locations and facilities that provide comprehensive HIV/PMTCT services. The team consisted stakeholders including state Ministry of Health, State AIDS/STI control Program (SASCP), State AIDS control agency (SACA), Primary Health care development board, academia, the Lead partner, Civil society organizations, Religious groups and Persons Living with HIV/AIDS (PLHIVs) majorly.

The challenges were reviewed in the background of dense populations of these urban slums, with opportunities to scale up PMTCT into the communities. The gaps in coverage and barriers to accessing HIV/PMTCT services were discussed at the State HIV technical team meeting. Discussions centered on improving coverage and access by increasing number of HIV providing facilities and provide services within communities using acceptable, affordable and assessable strategies and resource persons. These would require community oriented resources and leverage existing $\mathrm{MNCH} / \mathrm{PMTCT}$ structures to facilitate uptake. They accepted the need to scale-up HIV/PMTCT into the affected communities, proposed scale up strategies, ratified suggested resource persons and agreed on identifying health facilities. The stakeholders agreed on the need to collaborate with the Lead IP and the platform would be through a small organization that could act as sub-contractor. All efforts were to bridge exiting gaps emanating from loss of trust associated with the Jos crises.

\subsection{Community Resource Persons Engagement Process}

This core team identified other persons including Community Youth Leaders, Facility owners, Women Leaders, Islamic clerics and Persons living with HIV and AIDS (PLHIVs). Stakeholder engagement included religious leaders, federation of Muslim women association of Nigeria (FOMWAN), traditional birth attendants (TBAs) and known PLHIV expert patients residing within these communities.

The Lead IP program office and JUTH HIV clinic staff provide support, guidance and technical support to the team and their sites, based on safety considerations.

\subsection{Stakeholders Meeting}

A stakeholders' meetings were convened to engage them on the program, obtain buy in and ensure program ownership. The stakeholders included community gate keepers, HIV implementing partners, the SMOH, SASCP, SACA, members of CSOs, TBA groups operating in the target communities, PLHIV support groups and leaders and other stakeholders were engaged, agreed with the challenges of the conflict and the gaps in accessing HIV/PMTCT and $\mathrm{MNCH}$ services in the communities based on the rising insecurity. The communities that were most affected were identified and agreed at during the meeting, and the mandate was given to the team to identify appropriate facilities for PMTCT service delivery. The various options to approaching the challenge and scaling up services in the communities were deliberated upon, and together the concept of starting up a faith based community based organization that would anchor the process was agreed upon. The formation of the NGO to speak to the aims and objectives of the Project was then initiated.

\subsection{Birth of the Non-Governmental, Faith Based Community Organization}

The MUHIN team registered the initiative as nongovernmental, nonprofit faith-based community organization aimed at preventing spread of HIV/AIDS and providing HIV treatment, care and support services by gaining entry through existing maternal and child health services. It was registered under the Cooperate affairs commission, Ministry of health and Ministry of women affairs. They deliberated with their stake holders, and for purposes of creating trust and acceptability to the target communities and persons, they named Muslim Health Initiative of Nigeria (MUHIN).

Their Mission is support health of persons in the disadvantaged target communities by providing comprehensive and quality HIV/AIDS and reproductive health services, and the health of women, girls and children would be priority.

The objectives included scaling-up HIV services using acceptable methods, integrating HIV/PMTCT into MNCH services; leveraging systems and gains of HIV programs to strengthen $\mathrm{MNCH}$ services and reduce maternal, newborn and child mortality rates. They would achieve this by building capacity and systems of partner facilities, which would be strengthened and supported for PMTCT by upgrading $\mathrm{MNCH}$ services and structures for quality HIV/PMTCT service delivery. The Lead IP supported the concept targeted at meeting unmet PMTCT needs and provided funding in line with mandates of PMTCT saturation and support of small indigenous organizations for HIV service delivery.

\subsection{Signing of Memorandum of Understanding and Organizational Support}

The Lead IP engaged the MUHIN organization to provide HIV/PMTCT services, and they defined and agreed on roles 
of each party, targets and deliverables. These were concretized and documented in a memorandum of understanding to be a six month pilot project, to be renewed based on project outputs and funds availability. MUHIN as an organization, would receive organizational administrative support by the Lead IP, data capture equipment (computers and accessories), Monitoring and Evaluation tools, commodities and consumables for PMTCT/MNCH materials, training and mentorship for HIV/PMTCT project implementation. The MUHIN project and site staff would receive trainings for HIV counseling and testing, couple HCT, PMTCT, ART, Universal precautions, infection prevention and control, and Integrated Management of Adolescent and Adult Illness and Integrated Management of pregnancy and childbirth (IMAI IMPAC) using WHO Modules. These would build capacity of the majorly facility lower cadre staff using simple but standard curricular.

\subsection{Facility Engagement Strategies}

The strategies were to identify qualified facilities in communities lacking comprehensive HIV services by using available state data and carrying out facility assessment to access existing capacity and needs.

Improve coverage by identifying well utilized and registered $\mathrm{MNCH}$ facilities that can be upgraded and supported to provide PMTCT services. Utilize HIV/PMTCT service providers who reside or work within the communities and other community oriented resource persons for scale-up and improved accessibility of HCT, PMTCT and ART by linking facilities using the hub and spoke model.

\subsubsection{Facility Identification and Assessment}

At the stakeholders meeting, well utilized community facilities providing $\mathrm{MNCH}$ services were identified as potential to address Gaps and unmet HIV/PMTCT needs in these communities. About fifty-seven private/faith based clinics providing ANC, delivery and general health services were identified. Additional assessment criteria included status of facility headship, proper registration and number of ANC monthly enrollees. Facilities headed by formally trained health workers (Doctors, Nurses, Community Health officers/Workers and Laboratory Scientists), those registered with Ministry of Health who enroll above thirty monthly ANC cases were selected, and twenty-nine health centers in fifteen Islamic communities were thereafter selected for assessment.

The assessment team comprised five of the core MUHIN team and one program officer from the Lead partner. Stakeholders including SASCP and SACA were involved in planning the assessments but could not participate because of widespread fear. The program officer who provided oversight, was fluent in the Hausa language and familiar with community culture, but dressed acceptably because of differences in ethnicity/religion. A two week on-site needs assessment was carried out, and technical support and funding was provided by the Lead IP, and twenty-eight facilities located majorly in Jos North were selected for the project.

A structured and modified tool was used to assess the facilities. The parameters assessed included

Facility Details- Government registration, services provide and Location details

Laboratory -Space, facilities, equipment and tests conducted

Administration and Staffing- Headship, Finance/Administration Systems, and total facility staff disaggregated by cadre.

Infection Prevention and Control- Waste and Sharps disposal

Utilities- Light and Water availability

Monitoring and Evaluation- Data collection and national $\mathrm{M} / \mathrm{E}$ tools

Services delivered particularly MNCH- Labour ward and delivery couch availability, essential Obstetric care services and Commodities, Universal precaution materials and appropriate instruments

Clinical Management Space- waiting area, Chairs, couches, consulting rooms and privacy

Recommendations, identified needs and follow up actions

\subsubsection{Summary of Assessment Findings}

All facilities are private and majorly faith based, with eleven facilities headed by Doctors, five by Nurses, three by Community health officers, eight by Community Health Extension workers and one by laboratory scientist.

The facilities headed by Doctors provided HIV testing routinely, with no standard pre or posttest counseling. No facility had support for HCT/HIV services and Rapid test kits (RTKs) are bought erratically from the open market and patients paid for HCT. There was no evidence of structured HCT points or use of National HCT Algorithm in any facility. Record keeping was suboptimal for MNCH and HIV, and no facility had any national MNCH or HIV registers. HIV testing in labour is not offered in about all clinics and staff had no form of HIV training.

All facilities provided various forms of $\mathrm{MNCH}$ services including antenatal care and delivery services for twenty four hours and each had minimum of two nurses or midwives or CHEWs. All facilities have designated labour rooms and delivery beds except one which is said to be a demonstration clinic where ANC is offered but deliveries are not taken. Commodities and simple instruments for basic essential obstetric care were satisfactory in the doctor led facilities, who provided more comprehensive $\mathrm{MNCH}$ services than the others. The universal precaution materials including sharps disposal containers were inadequate across all the facilities.

Twenty-four facilities have functional but small laboratories and were able to provide simple tests like urinalysis, pregnancy tests, packed cell volume and malaria parasites tests majorly. Three of the doctor led laboratories had laboratory technicians, and together with the one led by a laboratory scientist were able to provide full blood count and microscopy and culture. The twenty remaining laboratories were manned by laboratory assistants or CHEWs, while the 
four facilities lacking laboratories send specimens to other laboratories outside.

The doctor led sites all had dedicated drug storage spaces and pharmacy technicians that catered for the medications, while the other facilities had a CHEW or facility head taking care of the drugs.

All clinics were connected to the National electricity grid, but light was not constant in any, which they substituted with fuel generators or battery run lamps, while water was majorly obtained from wells or boreholes.

In all hospitals, open waste burning was the final waste disposal method, but placenta was given to family members, while blood and human waste were washed into toilets and/or drains.

The areas requiring strengthening include quality essential obstetric care, documentation, record keeping, universal precautions, training and support to provide HIV/AIDS services, infection control and waste management.

\subsection{Human Resources for Health (HRH) Training and Facility Development}

The first group of trainings targeted the MUHIN project team and focused on organizational support, leadership, supportive supervision and systems strengthening. The six core MUHIN team members received trainings on integrated supportive supervision, finance and administration, Project management and Monitoring and evaluation. They also participated in site trainings based on their program areas and received support to provide leadership.

The second group of trainings targeted MUHIN facilities staff across all HIV program areas. They received trainings for HCT/couple HCT, PMTCT, ART, infection prevention/control and PMTCT. Simplified but standard curricular based on National HIV Guidelines were utilized. MUHIN engaged two CORPs for each facility, comprising female PLHIVs, TBAs and FOMWAN members. They were to receive infection prevention and basic care and support training and monthly recharge card/transportation stipends.

\subsection{HIV Service Delivery}

The PMTCT services will be integrated into $\mathrm{MNCH}$ services including HCT in ANC, intrapartum care, delivery and child health settings. Also HCT will be provided to men, non-pregnant women and children at immunization clinics, OPDs and during community outreaches. ARVs will be provided for mother baby pairs for PMTCT and others would receive ART according to National guidelines. ART sites will receive Point of care (POC) equipment while Our lady of Apostle (OLA) hospital, Jos, a comprehensive HIV site, will provide Viral load and Early Infant diagnosis (DNA PCR) in the interim. Samples will be pooled from the three ART sites, transported to OLA Laboratory and results retrieved and distributed by MUHIN laboratory focal person.

\subsubsection{Service Delivery and Site Upgrades}

All sites received universal precaution materials including aprons, boots, gloves, goggles, mackintosh, injection safety boxes, bin boxes for medical and none medical waste, buckets, cleaning utensils, disinfectants and bleach. Facility optimization was discussed and they were given instruments for their labour wards including galley pots, kidney dishes and tissue forceps. They received Job aids, charts, standard operating procedures, protocols and Nigerian National guidelines on HCT, PMTCT and ART.

\subsubsection{Commodity and ARV Logistics}

A system was developed for regular supplies utilizing the hub and spoke model, where the three ART hospitals were hubs. They would receive Rapid test kits, ARVs and drugs for Opportunistic infections and distribute to respective spokes. The Lead IP pharmacist collaborated with MUHIN team and JUTH Pharmacist to provide drug logistics and data capture for MUHIN sites.

\subsubsection{Monitoring and Evaluation}

Site records clerks/CHEW were identified and received basic data capture training. They were taught client enrolments, the provision of facility and project identifiers for HCT, PMTCT, HIV Exposed infants and ART and provided given cabinets for patient folders. National M/E tools were provided to MUHIN sites for HCT, PMTCT and ART and support was provided for utilization and data entry. The Lead IP provided delivery registers and provided to support and strengthen $\mathrm{MNCH}$ and facility records keeping.

\subsubsection{Governance}

Facility heads identified focal persons for each site who received orientation on providing leadership to their site HIV programs, providing quality care, meeting targets, submitting reports and providing supportive supervision to staff.

\subsubsection{Site project Financing}

Each site received funds for sample transportation and basic commodities like spirit, gauze, cotton wool, needles and syringes and a monthly imprest. They received documents stipulating funders' requirements, finance books and submission timelines.

\subsection{CORP Facility Engagement Model}

MUHIN engaged the twenty eight selected facilities to provide various forms of HIV services based on their human capacity and facility competence. The hub and spoke model would be used, and all the facilities would provide HCT. HIV services were made available at all the identified health facilities, however not all clinics have the capacity to give triple anti-retroviral drugs. Out of the 28 clinics, the 17 clinics that were not led by medical doctors would provide HCT alone, while the remaining 11 doctor led would provide HCT and PMTCT. Three of the clinics providing HCT and PMTCT were selected based on clientele, laboratory capacity and location to provide comprehensive HIV treatment, care and support.

The twenty eight facilities would provide HCT in all settings (including $\mathrm{MNCH}$ ) and provide intrapartum ARVs to women testing positive in Labour. These are the none doctor 
led facilities and they will refer all HIV positive pregnant women to the eleven facilities that will be providing triple ART for PMTCT based on the National Guidelines. However, eight of these PMTCT facilities will feed into three other sites, with higher clientele and staffing, that will provide ART and comprehensive HIV services, to which they will refer males, children and female PLHIVs in non ANC settings. A female PLHIV expert patient is anchoring the referrals and linkages among sites, working with site focal referral persons.

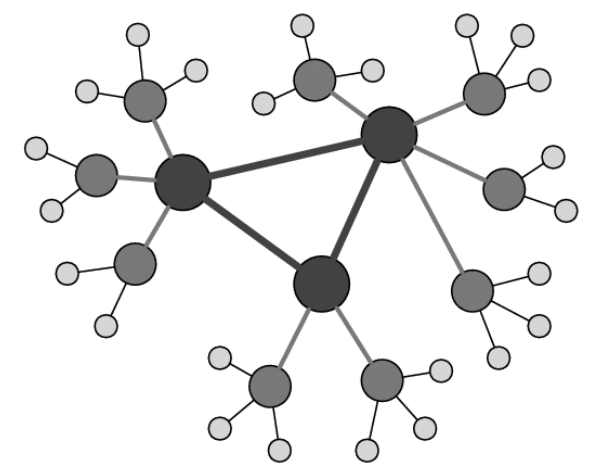

Figure 2. Hub and Spoke Model of Linking HCT facility to PMTCT facility to ART facility [34].

Black Dots are ART facilities

Dark grey Dots are PMTCT facilities

Light Grey Dots are HCT facilities

Considering Nigeria's Human resources for health (HRH) crises, especially in fragile and conflict environments, the principles of task shifting and task sharing (TSTS) strategies will be utilized as designated in the National TSTS guidelines, so that CHEWS, TBAs and experienced PLHIVs (expert patients) will provide service delivery as approved. Mentorship and supportive supervision will be provided by MUHIN Team with support from APIN Jos Program office.

\section{Project Results}

A total of twenty eight sites were selected, upgraded and provided capacity building provided services and reports on the MUHIN project. They were able to improve quality of $\mathrm{MNCH}$ services in addition to addition to bringing PMTCT services into the community.

\subsection{Human Resources for Health (HRH) Capacity Development}

\subsubsection{HCT and Infection Prevention}

Training was conducted for 46 healthcare workers from MUHIN sites. Injection safety and waste management training was conducted for forty healthcare workers and 25 waste handlers.

\subsubsection{Adult ART}

Training was conducted for 25 staff including doctors, nurses, pharmacy technicians and CHEWs at the twentyeight MUHIN sites.

\subsubsection{PMTCT}

The Integrated Management of Adolescent and Adult Illness and Integrated Management of pregnancy and childbirth PMTCT (IMAI/IMPAC/PMTCT) training was conducted for 33 nurses, CHOs and CHEWs across all sites.

\subsubsection{Paediatric Treatment}

Nine site staff from the three ART sites received paediatric HIV training (Six doctors and three nurses).

\subsubsection{Laboratory Training}

Eight laboratory personnel from eight PMTCT/ART MUHIN sites received sample collection and cataloguing training. Training on Monitoring and Evaluation tools was provided during the HCT, PMTCT and ART to 27 Records clerks/CHEWs.

\subsubsection{Community Resource Persons Training}

A total of fifty-two PLHIVs, TBAs and FOMWAN members were attached to facilities, and received infection prevention, Home based care and basic care and support trainings to provide community home based care, tracking, adherence counselling and treatment support. They would receive monthly stipends for recharge card and transport.

\subsection{Support Infrastructure and Equipment for the Organization and Site Development}

All MUHIN sites received basic upgrades in the maternity units based on individual needs including waiting area furniture, thermometers, foetoscopes, stethoscopes, weighing scales and Sphygmomanometers, useful for $\mathrm{MNCH}$ and other hospital patients.

\subsubsection{Support Systems Development to Support HIV and MNCH Services}

Each site received veronica buckets, liquid soap, paper towels, universal precaution materials including aprons, boots, gloves, goggles, mackintosh, injection safety boxes, bin boxes for medical and none medical waste, buckets, cleaning utensils, disinfectants and bleach were provided. Labour wards received kidney dishes and tissue forceps, while Job aids, charts, standard operating procedures, protocols and National guidelines on HCT, PMTCT and ART were provided.

\subsubsection{Commodity and ARV Logistics}

Systems were developed for medical supplies using the hub and spoke model where the three ART hospitals were hubs. They received Rapid test kits, ARVs and drugs for Opportunistic infections like Cotrimoxazole and distributed to respective spoke facilities. The Lead IP pharmacist and MUHIN team coordinated monthly forecast and distribution.

\subsubsection{Monitoring and Evaluation Systems}

Site records clerks/CHEWs gained competency in client enrolment, providing facility/project identifiers for HCT, PMTCT, HIV Exposed infants and ART, and stored patients records confidentially. Sites received patient folders and National M/E tools for HCT, PMTCT and ART. Facility staff 
were supported till proficiency and correct utilization commencement.

\subsubsection{Governance}

Facility heads obtained skills in providing leadership to site HIV programs, meeting targets, submitting quality reports and provided supportive supervision to staff for HIV service delivery.

\subsubsection{Project Financing}

Funders' requirements were upheld including finance books documentation, adherence to submission timelines and principles of allowable expenses.

\subsection{Developing Community Systems}

The MUHIN team engaged female community expert patients who had completed the PMTCT cascade that produced HIV negative infants. Their complimentary roles along the HIV care and treatment continuum included demand creation, treatment support, drug adherence, linkage to care, mother-to-mother (M2M) PMTCT mentors, home based care, infant follow-up and retention support.

MUHIN also engaged community TBA associations for HIV awareness creation, referring/escorting pregnant women for HCT/PMTCT/MNCH services at target facilities. The Federation of Muslim Women's Association of Nigeria (FOMWAN) in Jos, was engaged to create HIV/PMTCT awareness, demand creation and debunk community myths about HIV/PMTCT. FOMWAN engaged the Nigerian Union of Road Transport workers (NURTW), advocate support for their wives to access PMTCT/MNCH services and assist in transporting women in labour with/without complications to health facilities.

\subsection{Site Activation for Commencement of HIV Services}

The HIV/PMTCT systems were successfully set up at all twenty eight sites. The core MUHIN team and organization had been well set up and started providing leadership to set up service delivery. The Commodity logistics had been structured and the sites were ready to commence services. The activation of sites would be the second phase of the program, with a flag off by the Lead IP State team Lead, the Director General of the State AIDS control Agency (SACA) and the State AIDS program coordinator.

\section{Discussion}

In the face of unmet PMTCT needs and gaps, objective analysis of the context of existing challenges and factors perpetuating unmet needs are critical. The PMTCT diagnostics should be conducted and the findings should inform identification and implementation of context specific strategies to close existing HIV/PMTCT service delivery gaps. Well-articulated plans should be well in place ahead of implementation to ensure a successful PMTCT program with positive outcomes.

International $\mathrm{HIV}$ and humanitarian communities agree that HIV prevention, care and treatment can and should continue in emergencies and should include the provision of and scale-up of PMTCT services [36], and the guidelines have been modified to include continuation of services [37]. This is challenging when conflict occurs in countries/communities with background unmet PMTCT needs that require community entry and pioneer scale-up efforts. The unsafe terrains associated with conflict and displacement pose additional dimensions of accessing PMTCT/MNCH services, like that experienced in Jos, which threatened the health and security of all.

The WHO developed frameworks to demonstrate roles/reinforcements of relationships between individuals, family, community contexts, and health determinants including sociocultural values, policies, social norms and status of women [38]. Others inequalities are poverty, malnutrition, regional inequities and weak healthcare systems which are reinforced by ethnoreligious conflicts, poor road infrastructures and socio-cultural taboos and hinder access to healthcare [39].

Spaces must be created for community engagement, to hear voices of primary $\mathrm{MNCH}$ service beneficiaries, and receive their inputs into socially and culturally acceptable interventions [40]. Voices of men, older women, TBAs and community gatekeepers (religious, traditional) are critical in determining women's access and utilization of maternity services [41]. Relevant stakeholders and gatekeepers were involved in this project from MUHIN project outset.

Task shifting and sharing was implemented in this project since The Nigeria Presidential Summit Declaration of March 2014 on Universal Health Coverage (UHC) recognized shortage and mal-distribution of human resources for health (HRH) among health systems' challenges for achieving UHC [35]. It recommends that Governments ensure their health facilities have minimum numbers and skill mix defined for $\mathrm{HRH}$ at each level, focusing priority areas including Family and $\mathrm{MNCH}$ among others in Essential health services package. Recommendation 20 of the National TSTS policy document [35] indicates that CHEWs, Junior CHEWs and CHOs can safely and effectively provide specific services within health facility and community healthcare delivery using task shifting approaches. Recommendation 21 indicates that PLHIVs who are not trained health workers will be empowered to take responsibility for certain aspects of their care. They can also provide specific services for the care and support of others, particularly self-care and overcoming stigma and discrimination. Recommendation 22 indicates Cadres including pharmacists, pharmacy technicians/technologists, laboratory technicians, records managers, administrators and others, will be included in task shifting approach to provide full spectrum of health services.

Social factors create barriers to accessing $\mathrm{MNCH}$ services and failure of $\mathrm{MNCH}$ programs to address social health determinants affecting Nigeria's socially disadvantaged communities, poor community engagement mechanisms, exclusion of CORPs, especially TBAs perpetuate poor outcomes and mediated Nigeria's failure to achieve 2015 
MDG targets [42]. MDG interventions homogenized Nigerian women by being blind to diversities of multiethnic society possessing varying cultural norms that intersect with health, but adopted uniform approach across communities, with no visible attempts at engaging men/boys, who determine SRH outcomes of women concluded [38]. They also found while reviewing the midwives service scheme (MSS) outcomes, that failure to consider sociocultural norms, religion and ethnicity contributed to poor MSS/MNCH outcomes, because Southern Nigeria midwives were posted northward, where cultural and ethnoreligious differences created barriers between midwives and community women, who avoided PHCs but continued patronizing unskilled, but culturally accepted TBAs [43]. These considerations are directly related to uptake and utilization of MNCH/PMTCT services and informed the engagement of same religion/ethnicity CORPs on this project.

The National Health policy [43] theorizes that resilient health systems assure sustainable access to healthcare including $\mathrm{MNCH}$, thus attributing health outcomes to health systems performance. However, only focusing on improving numbers of hospitals and interventions, without considering varying challenges that women from well over 250 ethnic groups face that affect their access to MNCH/PMTCT services, will improve coverage but not necessarily access/utilization/retention in care.

Peer and community interventions including support for timely access to PMTCT services and retention in care are central for improved $\mathrm{MNCH}$ outcomes. The mothers-2mothers (M2M) mentor model where mothers PLHIVs in six sub-Saharan African countries receiving Option B+ PMTCT interventions had retention rates of $90.9 \%$ among M2M groups versus $63.6 \%$ in control group, one year after starting treatment. The M2M mothers had higher disclosure, practiced safer sex self-sufficiency, had increased access to PMTCT services, greater coping ability and improved psychosocial wellbeing compared to control group. These demonstrate that consistent community and peer support should be prioritized for successful PMTCT [44].

\section{Conclusion}

Context specific strategies need to be utilized in closing gaps of HIV service delivery including PMTCT and the scale up of services. To successfully prevent MTCT of HIV, countries must intervene at the community level, through PMTCT programs whose interventions need adopt multiple strategies including male involvement, peer mentorship, use of community health workers, mobile phone-based reminders, training of midwives, integration of PMTCT services, and enhanced referrals. Community-based approaches and resources are essential because many barriers preventing uptake of PMTCT services occur at community level and effective programs seek to improve rates of enrolment, retention in care and successful outcomes among mother-baby pairs. [45]

HIV/PMTCT Program managers require innovative but acceptable strategies to scale-up service delivery and close exiting gaps, and PMTCT interventions also strengthen other aspects of $\mathrm{MNCH}$ services.

\section{Recommendations}

This paper recommends that the one size fits all approach to scale up of HIV/PMTCT services does not fit all scenarios, not even when they are in the same country or region. Context specific challenges must be factored into the approach and diagnostics must inform strategy to be utilized. The voice of the beneficiaries must count, and we recommend that stakeholders' engagement and/or formative evaluations should be carried out to obtain and input the desires of the beneficiary communities into the project from the onset to the conclusion, and as well involve them in project implementation. Community engagement is crucial to project success and acceptability, especially in scenarios where conflict has caused division among people and should be utilized for project success in any community. The paper also recommends proper planning phase to include health systems strengthening ahead of scale up of PMTCT. Peace building is critical for the success and sustainability of HIV/PMTCT Projects.

\section{References}

[1] Avert. HIV and AIDS in Nigeria. Global Information and Education on HIV and AIDS. https://www.avert.org/professionals/hiv-around-world/subsaharan-africa/nigeria.

[2] National Agency for the Control of AIDS (NACA). Key HIV Statistics in Nigeria. Fact Sheet: HIV Prevention Program. https://naca.gov.ng/fact-sheet-hiv-prevention-program/.

[3] UNAIDS 2016. Prevention Gap Report. https://www.unaids.org/sites/default/files/media_asset/2016prevention-gap-report_en.pdf.

[4] World Economic Forum (2017). The Global Gender Gap Report http://www3.weforum.org/docs/WEF_GGGR_2017.pdf.

[5] PEPFAR (2016) 'Nigeria Gender Assessment' [pdf].

[6] Makama, G. A. (2013) Patriarchy and gender inequality in Nigeria: the way forward. European Scientific Journal June 2013 edition vol. 9, No. 17. Available at https://doi.org/10.19044/esj.2013.v9n17p\%25p.

[7] UNAIDS (2018) 'Start free, Stay free, AIDS free: 2017 progress report' [pdf].

[8] National Bureau of Statistics (NBS) and United Nations Children's Fund (UNICEF) (2017) Multiple Indicator Cluster Survey 2016-17, Survey Findings Report [pdf].

[9] National Agency for the Control of AIDS (NACA) 2012. Federal Republic of Nigeria Global AIDS Response. Country Progress Report, Nigeria, GARPR 2012. Abuja; 2012. Available http://www.unaids.org/en/dataanalysis/knowyourresponse/cou ntryprogressreports/2012countries/ Nigeria 2012 GARPR Report Revised.pdf UNAIDS 2012. Accessed 14/03/2021. 
[10] United Nations. The millennium development goals progress report. http://www.un.org/millennium/pdf/MDG Report 2012.pdf. Accessed 15/03/2021.

[11] NACA (2017) 'National Strategic Framework on HIV and AIDS: $2017-2021$ ' [pdf].

[12] Jos, Nigeria Metro Area Population 1950-2021. Available at https://www.macrotrends.net>cities Assessed 19/03/2021.

[13] Nyam, A. D., Ayuba, L. T. (2016). The Growth of Urban Slums and Conflicts in Nigeria: A Case Study of Jos and Environs 19802010. International Journal of Social Science and Humanity 6 (5): 364-369. May 2016. DOI: 10.7763/IJSSH.2016.V6.673.Available at

https://www.researchgate.net/publication/279232886 The Growt h_of_Urban_Slums_and_Conflicts_in_Nigeria_A_Case_Study_o f_Jos_and_Environs_1980-2010/references Assessed 23/01/2021.

[14] Nyam, A. D. and Ajiji D. Y. (2016). The growth of Urban Slums and Conflicts in Nigeria: A Case Study of Jos and Environs 1980-2010. International Journal of Social Science and Humanity 6 (5): 364-369. DOI: 10.7763/IJSSH.2016.V6.673. Available at https://www.researchgate.net/publication/279232886_The_Gr owth_of_Urban_Slums_and_Conflicts_in_Nigeria_A_Case_S tudy_of_Jos_and_Environs_1980-2010/citations accessed $23 / 0 \overline{3} / 2021$.

[15] Nyam, A. D. (2011). Colonialism and Intergroup Relations in the Central Nigeria Highlands: The Afizere Story, Aboki Publishers, Abuja, p. 205, 2011.

[16] UNAIDS (2010). HIV and conflict: Connections and the need for universal access. A Forced Migration Review special supplement

https://www.unaids.org/en/resources/presscentre/featurestories /2010/october/20101027fssecurityandconflict.

[17] Federal Ministry of Health (FMOH) National STI/AIDS Control Program, Abuja (2014). Integrated National Guidelines for HIV treatment and Care Technical report on National HIV prevention, treatment and care.

[18] Krause, J. (2010). A Deadly Cycle: Ethno-Religious Conflict in Jos, Plateau State, Nigeria. Geneva Declaration. A working Paper. https://reliefweb.int/report/nigeria/deadly-cycle-ethnoreligious-conflict-jos-plateau-state-nigeria Assessed 19/01/2021.

[19] Best, S. G. (2007) Conflict and Peace Building in Plateau State, Nigeria, Ibadan: Spectrum Books Ltd.

[20] International Crises Group. (2012). Curbing Violence in Nigeria (I): The Jos Crisis Report 196 / Africa 17 December 2012. Available at https://www.crisisgroup.org/africa/westafrica/nigeria/curbing-violence-nigeria-i-jos-crisis Assessed $19 / 01 / 2021$

[21] Ogbuleke, L. E. (2019). Democracy and Ethno-Religious Conflicts in Jos, Plateau State, Nigeria (2007-2012). Irish Interdisciplinary Journal of Science \& Research (IIJSR) (Quarterly International Journal) Volume 3, Issue 2, Pages 2944, April-June 2019, Available at SSRN: https://ssrn.com/abstract=3418857.

[22] Suleiman, T. (2011) "Saving the Killing Field Stakeholders Agitate Over the Reluctance of the Authorities to Implement the Recommendations of Different Panels On How to Restore Peace to Jos". Tell, March 21, Pp. 50-54. Thisday (2010) "Again Plateau Burns, 22nd, January.
[23] Human Rights Watch (HWR) (2005). Revenge in the Name of Religion: The Cycle of Violence in Plateau and Kano States. Vol. 17, No. 8 (A). May. New York: HRW. https://www.hrw.org/reports/2005/nigeria0505/ Assessed $19 / 01 / 2021$.

[24] The New Humanitarian (2005). 'Nigeria: Plateau State IDPs Face Daunting Obstacles to Return to "Home of Peace and Tourism." Available https://www.thenewhumanitarian.org/report/53098/nigeriaplateau-state-idps-face-daunting-obstacles-return-home-peaceand-tourism Assessed 19/01/2021.

[25] The New Humanitarian (2010). 'Our Lives Will Never Be the Same Again.' Available at https://www.thenewhumanitarian.org/news/2010/01/22/ourlives-will-never-be-same-again Assessed 19/01/2021.

[26] National Population Commission (2019). Nigeria Demographic and Health Survey. The DHS Program ICF, Rockville, Maryland, USA.

[27] Oyebode, T. A. (2020). Knowledge product tool Kit for managing and improving access to Sexual and Reproductive Health and Rights Services in Fragile and Humanitarian settings during COVID-19 pandemic and future epidemics. Share-Net International on LinkedIn: FINAL EDITED SRHR TOOLKIT. pdf Available At https://sharenetinternational.org/category/resources/access-to-quality-srhrservices-for-people-affected-by-conflict-fragility-and-crisis/.

[28] Jamestown Foundation, Northern Cameroon Under Threat from Boko Haram and Séléka Militants, 9 January 2014, Terrorism Monitor Volume: 12 Issue: 1, available at: https://www.refworld.org/docid/52e0e6d84.html accessed 27 July 2020.

[29] Padian NS, McCoy SI, Karim SS, Hasen N, Kim J, Bartos M, Katabira E, Bertozzi SM, Schwartländer B, Cohen MS. HIV prevention transformed: the new prevention research agenda. Lancet. 2011 Jul 16; 378 (9787): 269-78.

[30] Busza, J., Walker, D., Hairston, A., Gable, A., Pitter, C., Lee, S., Katirayi, L., Simiyu, R., \& Mpofu, D. (2012). Communitybased approaches for prevention of mother to child transmission in resource-poor settings: a social ecological review. Journal of the International AIDS Society, 15 Suppl 2 (Suppl 2), 17373. https://doi.org/10.7448/IAS.15.4.17373 Assessed 19/01/2021.

[31] International Planned Parenthood Federation. IPPF Comprehensive HIV Services Package. Available at https://www.ippf.org/sites/default/files/202007/IPPF\%20\%20 Comprehensive\%20HIV\%20Services\%20Package.pdf Assessed 12/01/2021.

[32] Coutsoudis A, Kwaan L, Thomson M. Prevention of vertical transmission of HIV-1 in resource-limited settings. Expert Rev Anti Infect Ther. 2010; 8 (10): 1163-75.

[33] Msellati P. Improving mothers' access to PMTCT programs in West Africa: a public health perspective. Soc Sci Med. 2009; 69 (6): 807-12.

[34] Coordination in hierarchical pickup and delivery problems using delegate multi-agent systems. Available at https://www.researchgate.net/publication/228902224_Coordin ation_in_hierarchical_pickup_and_delivery_problems_using delegate_multi-agent_systems/figures? $10=1$ assessed on $01 / 04 / 2021$. 
[35] Federal Ministry of Health, Nigeria (2014). Task-Shifting and Task-sharing Policy for Essential Health Care Services In Nigeria. Available at https://www.health.gov.ng/doc/TSTS.pdf assessed on $01 / 03 / 2021$.

[36] World Health Organization (WHO). Consensus statement. Delivering antiretroviral drugs in emergencies: neglected but feasible. 2006.

[37] UNAIDS, GAP Report, 2014.

[38] Abimbola, S., Okoli, U., Olubajo, O., Abdullahi, M. J., Pate, M. A. (2012) The Midwives Service Scheme in Nigeria. PLoS Med 9 (5): e1001211. Available at https://doi.org/10.1371/journal.pmed.1001211 Assessed 01/03/2021.

[39] Overseas Development Institute (2010) Millennium Development Goals (MDG) report card: measuring progress across countries. Overseas Development Institute2010 Millennium Development Goals (MDG) report card: measuring progress across countries. Available: http://www.odi.org.uk/resources/download/5027.pdf. (Assessed 03/03/2021).

[40] Acosta, M. (2016) 'India's Janani Suraksha Yojana: Global Health Transformations of a National Program and Dissipating the Right to Health'. Unpublished. Available at: https://www.academia.edu/29182185/Indias_Janani_Suraksha
Yojana Global Healths Transformations of a National Pr ogram_and_Dissipating_the_Right_to_Health (Äccessed: 15 March 2021).

[41] Health Partners international (2015) Health systems that work for women and girls- Project Report. Available at http://resources.healthpartners-int.co.uk/wp-

content/uploads/2016/09/Health-systems-that-work-forwomen-girls_Web-May2016.pdf Assessed 29/03/2021.

[42] World Health Organization (2015a) Trends in maternal mortality: 1990 to 2015: estimates by WHO, UNICEF, UNFPA, World Bank Group and the United Nations Population Division. Tools for improving data collection.

[43] Federal Ministry of Health Nigeria (2016). National Health Policy. Promoting the Health of Nigerians to Accelerate Socio-economic Development.

[44] Avert. Global Information and Education on HIV and AIDS 2015. HIV positive mothers thrive on peer support. Available at https://www.avert.org/news/hiv-positive-mothers-thrivepeer-support assessed 29/03/2021.

[45] Measure Evaluation. Community Based Indicators for HIV Programs. Prevention of Mother to Child Transmission of HIV. Available At https://www.measureevaluation.org/community-basedindicators/PMTCT/pmtct assessed 22/02/2021. 